\title{
Impact of mass customization on cost and flexiblity performances: the role of social capital
}

\author{
Frank Wiengarten ${ }^{1} \cdot$ Prakash J. Singh $^{2} \cdot$ Brian Fynes $^{3} \cdot$ Ali Nazarpour $^{4}$
}

Received: 3 July 2017 / Revised: 11 October 2017 / Accepted: 20 October 2017 /Published online: 4 November 2017

(C) Springer Science+Business Media, LLC 2017

\begin{abstract}
More than ever, companies have to cope with ever changing market conditions. Some companies have reacted to shortened product life cycles, constant changes in customer preferences and cost pressures by implementing mass customization practices. Mass customization has been hailed as a way to overcome the tradeoff between cost and flexibility performance. However, there is lack of consistent empirical evidence to demonstrate that this really is the case. We advance this debate by proposing that in order for mass customization to be more effective, a company needs to possess and utilize social capital (i.e., cognitive, relational and structured social capital) within their supply networks. This study uses primary survey data from 513 plants from nine countries collected by the Global Manufacturing Research Group (GMRG). We used structural equation modelling analysis to test our hypotheses. Results indicate that mass customization has the ability to improve a company's cost and flexibility
\end{abstract}

Frank Wiengarten

Frank.wiengarten@esade.edu

Prakash J. Singh

pjsingh@unimelb.edu.au

Brian Fynes

brian.fynes@ucd.ie

Ali Nazarpour

ali.nazarpour@mu.ie

1 ESADE Business School, Sant Cugat, Spain

2 University of Melbourne, Melbourne, Australia

3 UCD Smurfit School of Business, Blackrock, Co. Dublin, Ireland

4 School of Business, Maynooth University, Maynooth, Ireland performance. Furthermore, results regarding the moderating role of social capital are mixed. Cognitive capital only moderates the impact of mass customization on cost performance while relational capital increases this impact on both cost and flexibility performance. Structural capital does not moderate the impact of mass customization on performance.

Keywords Mass customization - Competitive strategy · Operational performance $\cdot$ Social capital

\section{Introduction}

Many companies are faced with changing customer preferences and continuous pressure to deliver customized products at a reasonable price (Chavez et al. 2012). It has been suggested that mass customization (MC), defined as "the ability of a firm to quickly produce customized products on a large scale at a cost comparable to non-customized products" (Tu et al. 2001, p. 203), can achieve cost and flexibility performance improvements simultaneously. Zipkin (2001) notes that MC represents a company's ability to offer individually tailored products or services on a large scale (Zipkin 2001).

While previously $\mathrm{MC}$ was regarded as merely a production and design concept, today MC has been introduced by various companies in multiple industries such as automotive, apparel, food, consumer electronic or health care (Gandhi et al. 2014; Nayak et al. 2015). To offer customized products on a mass scale, companies postpone the final production process to achieve flexibility and simultaneously low production costs. However, research has shown that companies have been struggling to simultaneously reap the cost and flexibility performance benefits promised by MC (van Hoek 1997; Fogliatto et al. 2012). While some companies may achieve greater flexibility 
through offering customized products at reasonable lead times, they may not be able to do so in a cost-effective manner (Squire et al. 2006). This study sets out to test some of the anecdotal and limited empirical evidence in confirming the performanceenhancing abilities of MC. The first of two research questions that explores this is: (1) Do mass customization practices simultaneously improve cost and flexibility performance?

Scholars have primarily focused on the importance and enabling role of technology in developing the MC concept. These include concepts such as solution space development, robust process design, and web-based customer choice navigation. For example, a key enabler of MC in the automotive industry has been the introduction of the modular platform concept (Mahmoud-Jouini and Lenfle 2010; Qu et al. 2011). However, researchers have focused less on the role of "softer organizational" resources and skills in order to develop MC. Huang et al. (2008) is one of a few studies that considered the role of intellectual capital in terms of learning on MC. They confirmed the importance of these managerial factors instead of the technological factors to develop MC across supply chains.

MC primarily operates at the supply chain level and that requires significant efforts and inputs from all participating entities across the supply chain (i.e., suppliers, customer, logistics, etc.) (Yao 2013). Supply chain management research has explored and confirmed the importance of social capital for the success of supply chains (Cousins et al. 2006; Lawson et al. 2008; Carey et al. 2011). According to Carey et al. (2011), social capital theory (SCT) is an important perspective to analyze connections and cooperation in supply chain relationships (McGrath and Sparks 2005). Social capital can be defined "as a valuable asset that stems from access to resources made available through social relationships" (i.e., supply chain relationships) (Lawson et al. 2008, p. 446).

In this study, we propose and test the moderating role of social capital for the success of MC practices. The level of success is defined in terms of the primary performance dimensions of cost and flexibility (Fogliatto et al. 2003). Specifically, this study, through a second research question, sets out to explore: (2) How important is social capital for the impact of mass customization on cost and flexibility performance? Social capital is conceptualized through the commonly referred to dimensions of cognitive, relational and structured social capital. Social capital such as trust, shared goals and objectives, and aligned processes and activities, are necessary to develop integrated supply chain processes and relationships. Integrating processes and relationships with supply chain partners is a crucial prerequisite for the success of MC. Previous research has established the performance enhancing abilities of social capital in supply chains. Thus, we believe that it is reasonable that these social capital dimensions can enhance the ability of MC to simultaneously improve a company's cost and flexibility performance.

\section{Literature review and hypotheses development}

MC represents a production and supply chain paradigm that combines value-added product customization with costefficiency closely related to mass production (Huang et al. 2008). The MC paradigm is a reaction to changes in customer preferences demanding customized products at reasonable prices. Through postponing the final production steps MC represents a theoretically superior production strategy to deal with demand uncertainty. Christopher (2000) stated that postponement is a vital element in any agile strategy (Christopher and Towill 2000). However, the concept of postponement on which MC largely rests is not new (Yang et al. 2004). Alderson noted in 1950 that postponing final assembly as late as possible promotes the efficiency of a marketing system (Alderson 1950).

Duray et al. (2000) conceptualized MC by defining its two most prominent subjects: (1) the basic nature of customization, and (2) the means for achieving customization at or near mass production costs. A customized product is designed, at least to some extent, to explicit customer specification. To customize a product the customer has to be involved in a part of the production cycle (i.e., design, fabrication, assembly, and use) (Duray et al. 2000). The earlier a customer is involved in the production cycle the higher the potential level of customization. Secondly, $\mathrm{MC}$ requires the production of unique products at relative low cost (Duray et al. 2000). Pine (1993) suggested that modularity in production is key to achieve cost-effective customized products. Technology has become a key factor for successful MC, whether in terms of supporting and enabling interactions with customers and suppliers or in the customization production process. Zipkin (2001) highlighted that MC should be approached cautiously - it requires unique operational capabilities (i.e. elicitation, process flexibility and logistics). Therefore, the success of MC relies on the exchange of timely and accurate information, which makes this practice complex and demanding to manage in order to reap its full benefits.

\subsection{Performance implications of mass customization: cost and flexibility}

The concept of MC has been developed with the intention to enable companies to offer its customers customized goods that are mass-produced. MC is supposed to overcome the trade-off between variety flexibility and cost (Westbrook and Williamson 1993; Tu et al. 2001). Tu et al. (2001) argued that an organization's MC is determined by "its ability to produce differentiated products with cost effectiveness, volume effectiveness, and responsiveness" (p., 203).

Previous research has investigated the performance implications of MC from a producer and customer perspective (Fogliatto et al. 2012). From a customer perspective, previous research has identified that the perceived customer benefit of 
MC stems from receiving a unique product that is individualized for a customer or group of customers at a reasonable price (e.g., Fiore et al. 2004; Squire et al. 2004). Additionally, ontime delivery has also been identified as an order winner from a customer perspective (Fogliatto et al. 2012). Tu et al. (2001) also tested the customer performance implication of MC. They identified that firms with the highest levels of $\mathrm{MC}$ also present the highest levels of value to customer (i.e., the customers' degree of satisfaction with the organization's products).

The operations and supply chain management literature has predominantly focused on the producer's perspective. Piller et al. (2004) examined whether or not MC pays off from a customer integration perspective. They identified that 'economies of integration' arise through (1) postponing some actives until an order is placed, (2) precise information about market demand, and (3) the ability to increase loyalty by directly interacting with each customer. Similarly, Jiang et al. (2006) identified the following three potential benefits of MC: (1) the gained surplus from offering each customer the ideal product; (2) extra revenue from price discrimination; and (3) reduced costs due to risk pooling under stochastic demand.

However, the empirical evidence regarding these potential performance improvement abilities have not yet been fully examined. In one of the earlier studies on MC, Ahlstrom and Westbrook (1999) tested the implications of MC on performance and identified that the benefits of $\mathrm{MC}$ are largely at the customer side rather than at the providers side in terms of costs and profits. Likewise, Squire et al. (2006) tested the impact of MC on tradeoffs in terms of cost, quality, delivery and flexibility. In contrast to the theoretical and anecdotal literature on $\mathrm{MC}$, they identified negative performance implications of MC on cost and lead-times.

Thus, while theoretically it has been argued that through postponement, standardization, inventory pooling, and agility, companies can simultaneously achieve economies of scale and scope, nonetheless there has been little or no empirical analysis of this proposition. Accordingly, we now frame our first research question with the following hypotheses:

H1 $1_{\text {(a): }}$ Mass customization has a positive impact on cost performance.

H1 $1_{(b)}$ : Mass customization has a positive impact on flexibility performance.

\subsection{Mass customization and the moderating role of social capital}

We apply SCT to analyze our second research question "how important is social capital for the impact of mass customization on cost and flexibility performance?" Through SCT we conceptualize and analyze a company's social capital, and its role on enhancing the efficacy of MC.
Social capital can be defined as the sum of the actual and potential resources that are embedded within, available through, and derived from the network (Nahapiet and Ghoshal 1998). SCT proposes that these networks are a valuable source of collectively-owned capital (Bourdieu 1986). SCT can be applied to analyze and characterize a company's relationships through focusing on the exchange of resources and information having performance implications (Koka and Prescott 2002). Nahapiet and Ghoshal (1998) categorize social capital into cognitive, relational, and structural capital. The cognitive dimension includes shared goals, vision and values between actors in a social system (Tsai and Ghoshal 1998). The relational dimension refers to trust, obligation, and identification present in personal relationships between actors (Nahapiet and Ghoshal 1998). And the structural dimension refers to the configurational linkages between people or units that the connectivity (Nahapiet and Ghoshal 1998).

Previous research has tended to focus on complementing MC with resources such as IT, process and production technology (Jitpaiboon et al. 2013). However, managerial abilities and intangible resources rather than technical resources such as social capital have long been largely neglected in this line of research (Huang et al. 2008). Through applying the knowledge-based view Huang et al. (2008) explored the role of intellectual capital in terms of internal and external learning on MC. They identified that internal and external learning lead to effective process implementation (i.e., a knowledge-based capability in which knowledge is embedded in a tangible process or equipment), which in turn enables MC. More recently, Zhang et al. (2015) tested and confirmed the enabling role of social capital on MC in terms of structural, relational and cognitive capital. Furthermore, other researchers have applied SCT in a more general supply chain setting (Carey et al. 2011), indicating the need for an optimal level of SC to develop trustful relationships and integrate processes with upstream and downstream members of the chain.

The success of MC depends on the interaction and process integration of all associated players in the supply chain network. From a downstream perspective customers are involved in customizing the product or service to articulate their specific needs (Salvador et al. 2009). And from an upstream perspective suppliers are involved in process and product integration to postpone the final product steps to introduce a push/ pull production paradigm. In order to successfully achieve this, at the supply network level, companies rely on their supply chain partners and on the social capital located in their network.

\subsubsection{Cognitive capital and the development of $M C$}

Cognitive capital has been conceptualized as a resource that provides shared representations and interpretations of meanings amongst network members (Nahapiet and Ghoshal 
1998). Inkpen and Tsang (2005) refer to shared culture and collective goals as the pillars of cognitive capital. Villena et al. (2011) concluded that cognitive capital results in committed parties getting a better understanding of behavioral norms and common goals within the network and relationship.

$\mathrm{MC}$ does not only rely on integrated processes and standardized and synchronized operations between internal and external partners but also on the intangible web of shared meanings and cultures (Rungtusanatham and Salvador 2008). To successfully adopt MC, companies need to share the same goals and vision for MC. In essence, MC is a supply chain practice that can only be successful if external integration between the relevant trading partners is achieved (Yao 2013). In this context, Houlihan (1985) notes that supply chain fragmentation could be eliminated through shared objectives and goals. However, this is especially challenging given the complexity of supply chains designed to deliver mass customized products. Objectives and goals change and differ along the supply chain. From the sourcing origin of the supply to the end customers $\mathrm{MC}$ requires a switch from a predominant focus on cost efficiency to a focus on flexibility at the customer end. When the overall goal of satisfying the customer is out of focus, $\mathrm{MC}$ becomes ineffective. Lower tier suppliers that are distanced from the customers tend to focus on efficiency while supply chain members that are closer to the customers tend to focus on flexibility. Lack of integration of these goals leads to ineffective MC. With the existence of cognitive capital, the strive for specific goals and objectives is supported through a common mind-set and attitude towards the necessary steps, attributes and practices. Although companies along the supply differ in terms of their operations strategy and thus process choice and production setup and individual supply chain design it is the cognitive capital, that fosters an understanding of each other's differences that can put the defragmented supply chain pieces (i.e. supply chain members) together.

Thus, we posit that when cognitive capital is present in a supply chain, companies can achieve higher levels of performance from MC. Accordingly we propose the following hypotheses:

$\mathbf{H 2} \mathbf{2}_{(\mathbf{a})}$ : The impact of mass customization on cost performance is positively moderated by cognitive capital.

$\mathbf{H} \mathbf{2}_{(\mathbf{b})}$ : The impact of mass customization on flexibility performance is positively moderated by cognitive capital.

\subsubsection{Relational capital and $M C$}

Relational capital has been referred to as trust, obligations, respect and a friendly relationship amongst network members (Granovetter 1985; Nahapiet and Ghoshal 1998; Villena et al. 2011). Villena et al. (2011) noted that through repeated transactions, network partners develop trust, norms of friendship and a reciprocal relationship. Trust has been identified as one of the key dimensions of relational capital (Nahapiet and Ghoshal 1998). Trust is the belief that somebody's intended actions are appropriate in a particular setting/relationship from the others point of view (Misztal 1996 in Nahapiet and Ghoshal 1998).

MC is technology-intensive where processes need to be standardized and automated. Processes are integrated from a technical perspective through IT enabling information sharing (Jitpaiboon et al. 2013). However, as discussed earlier, the success of MC also relies on the managerial aspect of operations. To customize mass-produced products at a reasonable cost and at reasonable lead times, companies need to collaborate in the development phase as well as in the manufacturing phase of the product with their external supply chain partners. Relational capital itself can be viewed as the intangible part of supply chain collaboration, which is key to supporting and enabling MC. Relational capital is also required to get the supply chain partners commitment, especially from an investment perspective. The benefits of setting up a supply chain that can delivery mass customized products are long-term, but the initial investments (in terms of technology, training and change) to do so can be prohibitively high in the short term. Thus, trust and commitment is required to implement MC throughout the supply chain.

As such, a trustful and respectful relationship is a key element supporting $\mathrm{MC}$ through enabling information sharing. Accordingly, we posit:

$\mathbf{H 3}_{(\mathbf{a})}$ : The impact of mass customization on cost performance is positively moderated by relational capital.

$\mathbf{H} \mathbf{3}_{(\mathbf{b})}$ : The impact of mass customization on flexibility performance is positively moderated by relational capital.

\subsubsection{Structural capital and $M C$}

Structural capital has been researched from multiple perspectives (Carey et al. 2011). One group of researchers have conceptualized structural capital in terms of network characteristics and have taken characteristics such as number of firms and their relationship to conceptualize structural capital (Burt 1992). Another group have solely focused on the information sharing aspect between firms as a surrogate for structural capital (Lawson et al. 2008). Others have conceptualized structural capital through the strength of social interactions, which in turn is also measured through multiple dimensions, including information sharing (Oh et al. 2004). In this paper, we focus on the level of standardization of processes, procedures and codified knowledge.

This social capital dimension represents an important support for the efficacy of MC. MC requires quick and accurate 
execution of decisions at the supply chain level. This not only requires readily available codified information that can be applied and distributed throughout the supply chain; it also requires the standardization of processes to decrease the complexity of MC. Through the standardization of processes, lead times are reduced and product standardization is achieved. In turn, databases with codified information need to be available and accessible throughout the supply chain. Additionally, in case of disruptions in the MC process, predefined procedures need to be developed and adopted throughout the supply chain in order to mitigate any possible interruptions. This is particularly important in today's global supply chains and dispersed manufacturing networks that are characterized by distance and diversity of the supply chain members. To foster communication, understanding and a more efficient process to exchange information structural capital is needed. This allows for a reduction in lead times while simultaneously increasing product variety without necessarily increasing production costs. Accordingly, we propose the following hypotheses:

H4 (a) : The impact of mass customization on cost performance is positively moderated by structural capital.

$\mathbf{H 4}_{(\mathbf{b})}$ : The impact of mass customization on flexibility performance is positively moderated by structural capital.

\section{Research method}

\subsection{Sampling and data collection}

To test the impact of MC on cost and flexibility performance, and to explore the moderating role of social capital, we utilized survey data collected by the Global Manufacturing Research Group (GMRG). Data (representing the 5th iteration of the survey effort) was collected in 2013 with a few companies added at the beginning of 2014 (Jan.-Feb.). Data was collected in multiple countries, which adds to generalizability of the results (see Table 1). We used a subset of the GMRG data that comprized of 513 manufacturing plants from nine countries.

On average, 1.7 individuals per company filled out the questionnaire. Furthermore, as expected a significant correlation exists between number of respondents and plant size.

We tested for non-response bias. We assessed this possible threat by comparing whether a statistical difference existed between early and late responses for selected variables (i.e., cost, flexibility and MC variables) (assuming that late responds could be treated as close representation of non-respondents). The result of $\mathrm{t}$-tests indicates that no statistically significant differences between these two groups exists. This suggests that potential non-response bias is relatively low.

Table 1 Sample specifics

\begin{tabular}{|c|c|c|c|}
\hline Country & Frequency & Industry & Frequency \\
\hline Australia & 23 & Food \& kindred products & 56 \\
\hline China & 30 & Tobacco products & 1 \\
\hline Croatia & 112 & Textile mill products & 8 \\
\hline Hungary & 37 & $\begin{array}{l}\text { Apparel and other finished products made from fabrics } \\
\text { and similar materials }\end{array}$ & 22 \\
\hline Ireland & 30 & Leather and leather products & 5 \\
\hline Poland & 79 & Lumber and wood products, except furniture & 24 \\
\hline Taiwan & 40 & Paper and allied products, & 16 \\
\hline USA & 83 & Printing, publishing, and allied industries & 7 \\
\hline Vietnam & 79 & Petroleum refining and related industries & 1 \\
\hline Total & 513 & Chemicals and allied products & 21 \\
\hline Size & Frequency & Rubber and miscellaneous plastics products & 39 \\
\hline $1-25$ & 105 & Primary metal industries & 18 \\
\hline $26-100$ & 177 & $\begin{array}{l}\text { Fabricated metal products, except machinery and } \\
\text { transportation equipment }\end{array}$ & 52 \\
\hline $101-250$ & 111 & Industrial and commercial machinery and computer equipment & 20 \\
\hline $251-500$ & 50 & $\begin{array}{l}\text { Electronic and other electrical equipment and components, } \\
\text { except computer equipment }\end{array}$ & 32 \\
\hline $501-1000$ & 26 & $\begin{array}{l}\text { Measuring, analyzing, and controlling instruments; photographic, } \\
\text { medical and optical goods; watches and clocks }\end{array}$ & 8 \\
\hline$>1000$ & 42 & Manufacture of motor vehicles, trailers and semi-trailers & 15 \\
\hline Missing & 2 & Manufacture of other transport equipment & 5 \\
\hline \multirow[t]{4}{*}{ Total } & 513 & Furniture and fixtures & 17 \\
\hline & & Stone, clay, glass, and concrete products & 18 \\
\hline & & Miscellaneous manufacturing industries & 128 \\
\hline & & Total & 513 \\
\hline
\end{tabular}




\subsection{Measures}

To measure $\mathrm{MC}$, respondents were prompted to indicate their degree of agreement with five statements assessing their plant's mass customization abilities. Items listed in Table 2 were measured on a scale of one to seven were one means strongly disagree, four refers to neutral and seven to strongly agree. Our items are adopted based on the measures by $\mathrm{Tu}$ et al. (2001). Respondents were asked multiple questions with regards to their ability of customization in terms of product volume and variety, while simultaneously keeping high levels of quality and responsiveness. To provide a more nuanced assessment of a company's MC abilities we opted for using a one-to-seven scale while Tu et al. (2001) only used a one to five scale. However, the items adopted from Tu et al. (2001) remain largely unchanged.

Operations performance was measured across the selected dimensions of cost and flexibility (Rosenzweig and Roth 2004; Shin et al. 2000). Cost and flexibility were measured through prompting the respondents to indicate their plant's performance compared to their major competitors. The scale ranged from one-to-seven where one means far worse, four means

Table 2 Survey items and confirmatory factor analysis results

\begin{tabular}{|c|c|c|c|c|}
\hline Construct & Mean & S.D. & Loading standardized & t-value \\
\hline $\begin{array}{l}\text { Mass Customization } \\
\text { Alpha. } 905 \\
\text { Please indicate your degree of agreement with the following statements assessing yo }\end{array}$ & 's mass & 1.24 & tion capability & \\
\hline We are highly capable of large-scale product customization. & & & .76 & 19.82 \\
\hline We can easily add significant product variety without increasing cost. & & & .78 & 20.59 \\
\hline We can customize products while maintaining high volume. & & & .85 & 23.28 \\
\hline We can add product variety without sacrificing quality. & & & .80 & 21.39 \\
\hline Our capability for responding quickly to customisation requirements is very high. & & & .85 & 23.27 \\
\hline
\end{tabular}

Operational Performance

How does your current performance compare with your main competitor(s)?

Cost performance

$\alpha=.798$

Labour unit costs

$\begin{array}{ll}4.32 & .99\end{array}$

Total product unit costs

Raw material unit costs

Flexibility performance

$\alpha=.808$

Volume flexibility

Mix flexibility

Cognitive Capital

$\alpha=.909$

This plant and its major external partners have common understanding about

what activities are best for our relationship.

This plant and its major external partners have shared objectives and visions.

This plant and major external partners share common language and codes

(e.g. special vocabulary, abbreviation, and technical terms).

This plant and its major external partners have common understanding about

the same concepts (e.g. good, fast, cost, quality).

This plant and its major external partners have similar behavioral rules and norms.

This plant and its major external partners have common values and culture.

Relational Capital

$\alpha=.800$

Generally, the plant's main customers are trustworthy.

Generally, the plant's main suppliers are trustworthy.

Structural Capital

$\alpha=.894$

Standard operating procedures are in place.

Much of this plant's knowledge is contained in manuals, archives, or databases.

We usually follow the sequence of written procedures and rules.

Processes in our plant are well defined.

$17.07 \quad .53$

$21.52 \quad 80$

$14.86 \quad 41$

$5.03 \quad 1.17$

64

.92

$18.09 \quad .85$

$15.18 \quad .55$

$4.91 \quad 1.03$

.72

18.18

.52

.76

19.56

.58

.77

19.93

.59

.84

22.44

.70

.84

$22.44 \quad .70$

.70

17.18

.49

$5.18 \quad 1.73$

$\begin{array}{lll}.80 & 18.23 & .64 \\ .84 & 19.05 & .70\end{array}$

$5.20 \quad 1.21$

$\begin{array}{lll}.69 & 17.22 & .47 \\ .80 & 20.10 & .64 \\ .87 & 24.06 & .76 \\ .94 & 26.85 & .89\end{array}$


similar and seven far better (see Table 2). Cost was measured through three items with regards to labour cost, product unit cost, and raw material unit cost. Flexibility was measured through volume and mix flexibility. The items reflecting these two performance dimensions have been progressively developed throughout several GMRG data collection efforts. The measurement properties of these performance variables have been established and confirmed numerous times in multiple publications (e.g., Wiengarten et al. 2011, 2013).

Furthermore, we have included multiple moderating variables in our models to test whether social capital can support the tradeoff capabilities of MC and thus collectively improve cost and flexibility performance. Specifically, we conceptualized social capital in terms of the distinct dimensions of cognitive, relational and structural social capital (Nahapiet and Ghoshal 1998). Respondents were asked to indicate their degree of agreement with multiple statements on a scale of one (strongly disagree) to seven (strongly agree) with four indicating neutral. Social capital was conceptualized in the dimensions of cognitive capital (six items), relational capital (two items), and structural capital (four items). Items regarding cognitive capital assess a company's ability to seemingly interact with its supply chain partners. Relational capital assesses the level of trust that the company has towards its suppliers and customers. Structural capital assesses the level of standardization of the company's processes, procedures, rules and knowledge management. Items are listed in Table 2.

In addition, we controlled for plant size through the number of employees. Sample descriptives are given in Table 1.

\subsection{Reliability and validity}

We conducted confirmatory factor analysis (CFA) to validate our measures and to confirm our proposed factor structure. In this section, we analyze and discuss validity and reliability of our model and measures (Anderson and Gerbing 1988; Nunnally 1978). Our proposed structure of the items measuring
$\mathrm{MC}$, two dimensions of operations performance and three dimensions of social capital resulted in a reasonably good fitting model $\left(\chi^{2} / d . f=2.07 ; \mathrm{RMSEA}=.046 ; \mathrm{AGFI}=.91 ; \mathrm{IFI}=.99\right.$; $\mathrm{NFI}=.97$; NNFI $=.98 ; \mathrm{RFI}=.97)$ indicating convergent validity (Bollen 1989). Furthermore, all factor loadings exceeded the value of .50 and the t-values were also relatively high (see Table 3) (Vickery et al. 2003). Finally, the factor loadings all exceeded twice the value of their associated standard error, which further indicates convergent validity (Flynn et al. 2010).

To test for discriminant validity, we conducted CFA using a constrained model with every possible pair of latent constructs and set the correlations between the paired constructs to 1.0 (Flynn et al. 2010). Results regarding $\chi^{2}$ differences indicate discriminant validity (Flynn et al. 2010; O’Leary-Kelly and Vokurka 1998). We calculated the square root of average variance extracted (AVE) to test and confirm discriminant validity (Hair et al. 2010). If the square root values of the AVE are greater than the inter-construct correlations additional support for discriminant validity would be provided. Results in Table 3 indicate that this is the case. Furthermore, it can be observed in Table 3 that the AVE values are all above .5, which supports the notion of convergent validity for our measures (Malhotra and Dash 2011). Finally, Cronbach's alpha $(\alpha)$ coefficients presented in Table 2 confirm the reliability of all the relevant constructs.

Before proceeding with the analysis of our structural model, we conducted common method bias assessment. While there were multiple cases with more than one respondent, which can reduce the possibility of common method bias, the possibility of this bias is still possible because of the content of the questionnaire and a single manager providing responses to the items of relevance to this study. Therefore, we tested for common method variance (Podsakoff and Organ 1986). We conducted Harman's one-factor test to evaluate the possibility of common method variance (Podsakoff et al. 2003). Thus, we loaded all items to a non-specified factor in an un-rotated factor structure. The first factor accounts for

Table 3 Correlations: Pearson, 2-tailed

\begin{tabular}{|c|c|c|c|c|c|c|c|}
\hline & (1) & (2) & (3) & (4) & (5) & (6) & (7) \\
\hline Mass Customization (1) & $.654(.808)$ & & & & & & \\
\hline Cost Perform. (2) & $.154^{* *}$ & $.578(.760)$ & & & & & \\
\hline Flexibility Perform. (3) & $.250^{* *}$ & $.284^{* *}$ & $.697(.834)$ & & & & \\
\hline Cognitive Capital (4) & $.418^{* *}$ & $.201^{* *}$ & $.284^{* *}$ & $.598(.773)$ & & & \\
\hline Structural Capital (5) & $.241^{* *}$ & $.213^{* *}$ & $.193^{* *}$ & $.568^{* *}$ & $.689(.830)$ & & \\
\hline Relational Capital (6) & $.266^{* *}$ & $.210^{* * *}$ & $.326^{* *}$ & $.476^{* *}$ & $.417^{* *}$ & $.673(.820)$ & \\
\hline Size (7) & -.026 & -.020 & .045 & .000 & -.040 & .015 & 1 \\
\hline
\end{tabular}

Value on the diagonal is the AVE and its square root in brackets

*** Correlation is sign. at the .01 level

* Correlation is sign. at the .05 level 
only $35.71 \%$ of total variance, and the independent (i.e., MC, social capital) and dependent variables (i.e., cost and flexibility) load on different factors. In acknowledging the shortcomings of this test, nonetheless, we view this as providing some evidence that common method variance does not appear to pose a serious threat in our study.

\section{Results}

To test the proposed model, we specified and calculated a SEM using Lisrel 8.8. Results presented in Table 4 indicate that $\mathrm{H}_{\mathrm{a}}$ and $\mathrm{H}_{\mathrm{b}}$ are supported. $\mathrm{MC}$ has a positive and significant impact on cost and flexibility performance. Furthermore, the model fit is adequate as can be seem from the results summarized in Table 4.

In $\mathrm{H} 2_{(\mathrm{a}, \mathrm{b})}, \mathrm{H} 3_{(\mathrm{a}, \mathrm{b})}$, and $\mathrm{H} 4_{(\mathrm{a}, \mathrm{b})}$ we proposed that cognitive, relational, and structural capital positively moderate the relationship between MC and, cost and flexibility performance and thus enhance the efficacy of MC. To test these hypotheses, we followed the approach suggested by Joereskog and Yang (1996), which uses a single cross-product indicator for the latent product. Previous research has shown that using a single cross-product indicator instead of the latent construct approach is not necessarily inferior to the procedure suggested by Jaccard and Wan (1995). Additionally, previous research in operations management has consistently used a median split approach to SEM with interaction terms, thus, losing information through converting continuous variables into categorical variables (e.g., Wiengarten et al. 2013).

We calculated the mean scores for MC, cognitive capital, relational capital, structural capital, cost performance and flexibility performance. We then continued following the suggestions by Joereskog and Yang (1996) to calculate the

Table 4 SEM path analysis: results for $\mathrm{H}_{(\mathrm{a}, \mathrm{b})}$

\begin{tabular}{lll}
\hline Hypotheses/ Path & \multicolumn{2}{l}{ Model 1 full model } \\
\cline { 2 - 3 } & Estimate & $t$-value \\
\hline H1 $_{\mathrm{a}}: \mathrm{MC} \rightarrow$ Cost Performance & $.19^{* * *}$ & 3.69 \\
$\mathrm{H}_{\mathrm{b}}: \mathrm{MC} \rightarrow$ Flexibility Performance & $.29^{* * * *}$ & 5.47 \\
Model Fit & & \\
RMSEA & .061 & \\
AGFI & .94 & \\
IFI & .98 \\
NFI & .97 \\
NNFI & .97 \\
RFI & .96 \\
$\chi^{2} / d . f$ & 2.89 \\
\hline
\end{tabular}

*** sign. at the .001 level; ${ }^{* *}$ sign. at the .01 level; ${ }^{*}$ sign. at the .05 level standardized (z-scores) values for the independent variable (IV) and moderators. Following this, we multiplied the moderators (i.e., cognitive, structural and relational capital) with the IV (i.e., MC) to calculate the final interaction terms (i.e., MC X Cognitive Capital, MC X Relational Capital, MC X Structural Capital). We ran a model with the IV, MC and the three interaction terms and the two DVs cost and flexibility performance.

Table 5 indicates that the results are mixed. Our findings suggest that while some social capital dimensions do positively moderate the $\mathrm{MC}$ - performance relationship, others do not confirm our hypotheses. Our results indicate that cognitive capital seems to only matter for the impact of $\mathrm{MC}$ on the cost performance dimensions. Cognitive capital does not seem to matter in terms of flexibility performance. Furthermore, while relational capital seems to consistently increase the impact of MC on cost and flexibility performance, structural capital does not moderate this relationship. A high level of structural capital does not lead to a stronger effect of $\mathrm{MC}$ on cost and flexibility performance. Overall, our results provide only partial support for our moderating hypotheses (H2-H4).

\section{Discussion}

This research was set out to explore the two interrelated research questions: (1) Do mass customization practices simultaneously improve cost and flexibility performance? And, (2) How important is social capital for the impact of mass customization on cost and flexibility performance?

Researchers and managers alike have tried to find solutions and practices to simultaneously achieve multiple performance objectives. And relatively recent market developments, led by changes in consumer preferences, have put increased pressure on companies to deliver unique and customizable products at an affordable price. Traditional operations and supply chain management based approaches are able to provide solutions for each objective (i.e., cost effective and flexible) individually. However, in achieving both dimensions simultaneously MC promises to be a practice to overcome the tradeoff between mass production (i.e., cost effective) and customization (i.e., flexibility).

The contribution of our research is twofold: Firstly, in providing a comprehensive assessment of the performance implications of $\mathrm{MC}$ in order to determine its tradeoff capabilities; and secondly, in assessing whether social capital can increase the efficacy of MC.

\subsection{Theoretical implications}

Exploring our research questions through a global dataset has enabled us to make multiple theoretical contributions. Our literature review has confirmed the claims of authors such as Fogliatto et al. (2012) that research on MC still needs some 
Table 5 SEM path analysis: results for $\mathrm{H} 2_{(\mathrm{a}, \mathrm{b})}, \mathrm{H} 3_{(\mathrm{a}, \mathrm{b})}, \mathrm{H} 4_{(\mathrm{a}, \mathrm{b})}$

\begin{tabular}{lll}
\hline Hypotheses/ Path & \multicolumn{2}{l}{ Model 2 interaction model } \\
\cline { 2 - 3 } & Estimate & $t$-value \\
\hline $\mathrm{H} 2_{\mathrm{a}}:$ MC X Cognitive Capital $\rightarrow$ Cost Performance & $.12^{* *}$ & 2.49 \\
$\mathrm{H} 2_{\mathrm{b}}:$ MC X Cognitive Capital $\rightarrow$ Flexibility Performance & .03 & .063 \\
$\mathrm{H} 3_{\mathrm{a}}:$ MC X Relational Capital $\rightarrow$ Cost Performance & $.09^{*}$ & 1.89 \\
$\mathrm{H} 3_{\mathrm{b}}:$ MC X Relational Capital $\rightarrow$ Flexibility Performance & $.10^{* *}$ & 1.96 \\
$\mathrm{H} 4_{\mathrm{a}}:$ MC X Structural Capital $\rightarrow$ Cost Performance & -.04 & -.71 \\
$\mathrm{H} 4_{\mathrm{b}}:$ MC X Structural Capital $\rightarrow$ Flexibility Performance & -.01 & -.13 \\
\hline
\end{tabular}

* sign. at the .1 level; ${ }^{* *}$ sign. at the .05 level further development. Specifically, we have found that while some performance aspects of MC have been explored in a piecemeal approach, a generalizable investigation across industry, company sizes and countries was still lacking.

We contribute to the existing literature in $\mathrm{MC}$ in exploring the performance debate of $\mathrm{MC}$ in terms of cost and flexibility. Confirmation of $\mathrm{H}_{(\text {(a) }}$ and $\mathrm{H}_{(\text {b) }}$ indicates that companies that are successfully implementing MC practices can simultaneously manage a cost efficient and flexible supply chain in terms of changing volume output and product offerings. Furthermore, we also tested for the potential role of the contingency "success factor" social capital in order to achieve these potential performance gains.

Specifically, we proposed and tested whether social capital supports MC in terms of performance implications for the cost and flexibility dimensions. We defined and conceptualized social capital through the actual and potential resources that are embedded within, available through, and derived from the network (Nahapiet and Ghoshal 1998). Multiple studies have started to explore the general role of social capital on supply chain management (e.g., Villena et al. 2011). The present study dives deeper into its role as we specifically explored its role on a key supply chain practice in the form of MC. We entangled the role of social capital in supply chains more comprehensively through exploring the combined role of MC and social capital to develop specific performance abilities from a cost and flexibility performance perspective.

We proposed that when companies have developed and accumulated high levels of cognitive, relational and structural capital with their supply chain partners they can expect higher performance gains in terms of cost and flexibility from their MC practices. However, adding the interaction terms into our SEM model revealed mixed results regarding their significance. We found that relational capital, conceptualized through trust between supply chain members, is a significant moderator for the MC - performance relationship. Indeed, relational capital marginally positively moderates impact of MC on cost and significantly on flexibility performance. Thus, the impact of $\mathrm{MC}$ on these performance dimensions is increased in the presence of relational capital. Previous research has constantly confirmed the pivotal role of trust in supply chain integration and collaboration aspects (Cai et al. 2010). We contribute to this stream of literature through confirming its important role for the success of MC.

Furthermore, we identified that cognitive capital solely acts as a moderator on the MC-cost relationship and not on the MC-flexibility relationship. Our results indicate that while cognitive capital may help MC to reduce cost, it does not increase the impact of $\mathrm{MC}$ on flexibility. Shared meaning and interpretations can streamline and increase the speed of the decision process. This can be viewed as vital for the success of MC as it relies on intense integration. However, it does not increase the impact of MC on flexibility. It could be the case that to achieve flexibility, social capital such as trust is much more important than cognitive capital because of the complexity of MC. Flexibility is a more complex performance objective that, in a network relationship, can only be achieved or increased through trust (Ferdows and De Meyer 1990).

Structural capital, on the other hand, does not appear to act as a moderator. Structural capital has been conceptualized in terms of the standardization of processes and procedures. It seems like this level of standardization is not particularly increasing the efficacy of MC. It might be that $\mathrm{MC}$ requires some degrees of freedom in terms of procedures and decision making to make it work (Hall and Johnson 2009).

\subsection{Managerial implications}

The results of our direct hypotheses should provide practitioners with more confidence to implement $\mathrm{MC}$ practices. It is an important finding to confirm that $\mathrm{MC}$ does overcome the cost - flexibility trade-off. Companies can simultaneously achieve cost and flexibility benefits through implementing MC practices. Shortening product life cycle and rapidly changing consumer preferences in terms of product individualism are all factors fueling the importance of MC. Our study has confirmed, using a large scale global survey, that companies can successfully react to these market demands through MC. This should provide managers with more conviction to 
implement MC practices to potentially increase their market share and thus being more competitive.

It is important to note that some social capital dimensions can support companies to achieve the performance goals promised by implementing MC. Our findings provide strong evidence of the importance of relational capital to enhance the efficacy of MC. Managers should thus support the development of relational capital when implementing or practicing MC. Developing trust at the network level can be achieved through multiple practices such as intensive communications, face-to-face meetings and such.

However, other social capital dimensions have not been identified as being supportive for MC. The social capital dimension of structural capital might be important for other practices or supply chain configurations but it seems not to be essential for the success of MC. This is important to note as the development of social capital is time intensive and costly (Villena et al. 2011). Furthermore, cognitive capital supports the efficacy of MC solely in the cost dimension. Accordingly, if companies can differentiate between these two performance dimensions and detect a performance discrepancy at the cost dimension managers should try to emphasize the development of cognitive social capital. However, this can only be achieved if the supply chain has a unifying goal or mission. Thus, it is important to communicate the importance of MC throughout the supply chain and across its members to achieve the full performance spectrum that $\mathrm{MC}$ promises.

The overall practical implications of this research are twofold. Firstly, MC can indeed deliver on the promises that it can improve the cost performance of companies while simultaneously increasing its flexibility in terms of volume and product variety outputs. Secondly, we can confirm that social capital is not only a general construct to manage a supply chain, but it can also improve the efficacy of MC mainly from a cost performance perspective. These findings were explored through a global survey in multiple manufacturing industries. Thus, we believe in the generalizability of our findings.

\section{Conclusion}

In this paper, we revisited the tradeoff debate of MC in terms of cost and flexibility performance. Furthermore, we tested if social capital can support MC to simultaneously improve a company's cost and flexibility performance. Our results confirm that MC can overcome the cost-flexibility tradeoff through simultaneously improve these operations performance dimensions. Furthermore, we confirm that some social capital dimensions (i.e., relational and cognitive capital) can support MC to further improve the cost and flexibility performance dimensions.

While relying on a large cross-country dataset enable us to generalize our findings across industries and countries, some limitations need to be noted. Firstly, we assess the implementation and performance implication of $\mathrm{MC}$ only from a focal company's perspective. However, since MC is a practice implemented at the network level, future research could try to measure its implication at the supply chain level. The same limitation applies to the social capital dimensions. Secondly, social capital is a dynamic construct that should ideally be measured as such. Thus, future research might be able design a longitudinal approach to assess the true implication of social capital at the supply chain level. Finally, our sample framing design is likely to be non-random. While we have the advantage of a large-scale cross-country database, the data collection suffers from this limitation, which needs to be noted when interpreting our results.

\section{References}

Ahlstrom P, Westbrook R (1999) Implications of mass customization for operations management. Int J Oper Prod Manag 19(3/4):262-274

Alderson W (1950) Marketing efficiency and the principle of postponement. Cost and Profit Outlook 3:15-18

Anderson JC, Gerbing DW (1988) Structural equation modeling in practice: a review and recommended two-step approach. Psychol Bull 103(3):411-423

Bollen KA (1989) Structural equations with latent variables. Wiley, New York

Bourdieu P (1986) The forms of capital. In Richardson, J.G. (Ed.), Handbook of theory and research for the sociology of education (p. 241-258). New York: Greenwood.

Burt RS (1992) Structural holes: the social structure of competition. Harvard University Press, Cambridge

Cai S, Jun M, Yang Z (2010) Implementing supply chain information integration in China: the role of institutional forces and trust. $\mathrm{J}$ Oper Manag 28:257-268

Carey S, Lawson B, Krause DR (2011) Social capital configuration, legal bonds and performance in buyer-supplier relationships. J Oper Manag 29:277-288

Chavez R, Fynes B, Gimenez C, Wiengarten F (2012) Assessing the effect of industry clockspeed on the supply chain management practice-performance relationship. Supply Chain Manag Int J 17(3):235-248

Christopher M (2000) The agile supply chain - competing in volatile markets. Ind Mark Manag 29(1):37-44

Christopher M, Towill DR (2000) Supply chain migration from lean and functional to agile and customised. Supply Chain Manag Int J 5(4): 206-213

Cousins PD, Handfield RB, Lawson B, Petersen KJ (2006) Creating supply chain relational capital: the impact of formal and informal socialization processes. J Oper Manag 24(6):851-863

Duray R, Ward PT, Milligan GW, Berry WL (2000) Approaches to mass customization: configurations and empirical validation. J Oper Manag 18:605-625

Ferdows K, De Meyer A (1990) Lasting improvements in manufacturing performance: in search of a new theory. J Oper Manag 9(2):168-184

Fiore AM, Lee SE, Kunz G (2004) Individual differences, motivations, and willingness to use a mass customization option for fashion products. Eur J Mark 38(7):835-849 
Flynn BB, Baofeng B, Zhao X (2010) The impact of supply chain integration on performance: a contingency and configuration approach. J Oper Manag 28(1):8-71

Fogliatto FS, da Silveira GJC, Royer R (2003) Flexibility-driven index for measuring mass customization feasibility on industrialized products. Int J Prod Res 41(8):1811-1829

Fogliatto FS, da Silveira GJC, Borenstein D (2012) The mass customization decade: an updated review of the literature. Int J Prod Econ 138:14-25

Gandhi A, Magar C, Roberts R (2014) How technology can drive the next wave of mass customization. McKinsey \& Company, New York

Granovetter MS (1985) Economic action and social structure: the problem of embeddedness. Am J Sociol 91:481-510

Hair JF, Black WC, Babin BJ, Anderson RE (2010) Multivariate data analysis, Seventh edn. Prentice Hall, Upper Saddle River

Hall JM, Johnson ME (2009) When should a process be art, not science? Harv Bus Rev 87(3):58-65

Houlihan JB (1985) International supply chain management. Int J Phys Distrib Mater Manag 15(1):22-38

Huang X, Kristal MM, Schroeder RG (2008) Linking learning and effective process implementation to mass customization capability. J Oper Manag 26:714-729

Inkpen AC, Tsang EWK (2005) Social capital, networks and knowledge transfer. Acad Manag Rev 30(1):146-165

Jaccard J, Wan CK (1995) Measurement error in the analysis of interaction effect between continuous predictors using multiple regression: multiple indicator and structural equation approaches. Psychol Bull 117:348-357

Jiang K, Lee HL, Seifert RW (2006) Satisfying customer preferences via mass customization and mass production. IIE Trans 38(1):25-38

Jitpaiboon T, Dobrzykowski DD, Ragu-Nathan TS, Vonderembse MA (2013) Unpacking IT use and integration for mass customisation: a service-dominant logic view. Int J Prod Res 51(8):2527-2547

Joereskog KG, Yang F (1996) Nonlinear structural equation models: the Kenny-Judd model with interaction effects. In: Marcoulides GA, Schumacker RE (eds) Advanced structural equation modelling techniques. Lawrence Erlbaum, Hillsdale

Koka BR, Prescott JE (2002) Strategic alliances as social capital: a multidimensional view. Strateg Manag J 23(9):795-816

Lawson B, Tyler BB, Cousins PD (2008) Antecedents and consequences of social capital on buyer performance improvement. J Oper Manag 26:446-460

Mahmoud-Jouini SB, Lenfle S (2010) Platform re-use lessons from the automotive industry. Int J Oper Prod Manag 30(1):98-124

Malhotra NK, Dash S (2011) Marketing research an applied orientation. Pearson Publishing, London

McGrath R, Sparks WL (2005) The importance of building social capital. Qual Prog 38(22):45-49

Misztal B (1996) Trust in modern societies. Polity Press, Cambridge

Nahapiet J, Ghoshal S (1998) Social capital, intellectual capital, and the organizational advantage. Acad Manag Rev 23(2):242-266

Nayak R, Padhye R, Wang L, Chatterjee K, Gupta S (2015) The role of mass customisation in the apparel industry. Int J Fash Des Technol Educ 8(2):162-172

Nunnally JC (1978) Psychometric theory. McGraw Hill, New York

O'Leary-Kelly SW, Vokurka RJ (1998) The empirical assessment of construct validity. J Oper Manag 16(4):387-405

Oh H, Chung MH, Labianca G (2004) Group social capital and group effectiveness: the role of informal socializing ties. Acad Manag J 47(6):860-896
Piller FT, Moeslein K, Stotko CM (2004) Does mass customization pay? An economic approach to evaluate customer integration. Prod Plan Control 15(4):435-444

Pine BJII (1993) Mass customization: the new frontier in business competition. Harvard Business School Press, Boston

Podsakoff PM, Organ DW (1986) Self-reports in organizational research: problems and prospects. J Manag 12(4):531-544

Podsakoff M, MacKenzie SB, Lee J, Podsakoff NP (2003) Common method bias in behavioral research: a critical review of the literature and recommended remedies. J Appl Psychol 88(5):879-903

Qu T, Bin S, Huang GQ, Yang HD (2011) Two-stage product platform development for mass-customisation. Int J Prod Res 49(8):2197-2219

Rosenzweig ED, Roth AV (2004) Towards a theory of competitive progression: evidence from high-tech manufacturing. Prod Oper Manag 13(4):354-368

Rungtusanatham MJ, Salvador F (2008) From mass production to mass customization: hindrance factors, structural inertia, and transition hazard. Prod Oper Manag 17(3):385-396

Salvador F, de Holan PM, Piller F (2009) Cracking the code of mass customization. MIT Sloan Manag Rev 50(3):71-78

Shin H, Collier DA, Wilson DD (2000) Supply management orientation and supplier/buyer performance. J Oper Manag 18(3):317-333

Squire B, Readman J, Brown S, Bessant J (2004) Mass customization: the key to customer value? Prod Plan Control 15(4):459-471

Squire B, Brown S, Readman J, Bessant J (2006) The impact of mass customization on manufacturing trade-offs. Prod Oper Manag 15(1):10-21

Tsai W, Ghoshal S (1998) Social capital and value creation: the role of intrafirm networks. Acad Manag J 41(4):464-476

$\mathrm{Tu}$ Q, Vonderbrembse MA, Ragu-Nathan TS (2001) The impact of timebased practices on mass customization and value to customer. J Oper Manag 19:201-217

Van Hoek R (1997) Postponed manufacturing: a case study in the food supply chain. Supply Chain Manag 2(2):63-75

Vickery SK, Jayaram J, Droege C, Calantone R (2003) The effects of integrative supply chain strategy on customer service and financial performance: an analysis of direct versus indirect relationships. J Oper Manag 21(5):523-539

Villena VH, Revilla E, Choi TY (2011) The dark side of buyer-supplier relationships: a social capital perspective. J Oper Manag 29:561-576

Westbrook R, Williamson P (1993) Mass-customisation: Japan's new frontier. European J Manag 11(1):38-45

Wiengarten F, Fynes B, Pagell M, de Burca S (2011) Exploring the impact of national culture on investments in manufacturing practices and performance: an empirical multi-country study. Int J Oper Prod Manag 31(5):554-578

Wiengarten F, Pagell M, Ahmed MU, Gimenez C (2013) Do a country's logistical capabilities moderate the external integration performance relationship? J Oper Manag 31(1-2):51-63

Yang B, Burns ND, Backhouse CJ (2004) Postponement: review and an integrated framework. Int J Oper Prod Manag 24(5):468-487

Yao JM (2013) Scheduling optimisation of co-operator selection and task allocation in mass customisation supply chain based on collaborative benefits and risks. Int J Prod Res 51(8):2219-2239

Zhang M, Lettice F, Zhao X (2015) The impact of social capital on mass customisation and product innovation capabilities. Int J Prod Res 53(17):5251-5264

Zipkin P (2001) The limits of mass customization. MIT Sloan Manag Rev 42(3):81-87 